\title{
ARTICLES
}

\section{Reduced Left Ventricular Function in Hypoxemic Newborn Pigs: A Strain Doppler Echocardiographic Study}

\author{
WENCHE BAKKEN BØRKE, THOR EDVARDSEN, DRUDE FUGELSETH, KJETIL LENES, HALFDAN IHLEN, \\ OLA D. SAUGSTAD, AND ERIK THAULOW
}

\begin{abstract}
Departments of Pediatric Research [W.B.B., O.D.S.], Cardiology [T.E., H.I.], and Pediatrics [K.L., E.T.], Institute for Surgical Research, Rikshospitalet University Hospital, N-0027 Oslo, Norway; Department of Pediatrics [D.F.], Ulleval University Hospital,
\end{abstract} N-0407 Oslo, Norway

\begin{abstract}
Myocardial dysfunction, hypotension, and increased pulmonary artery pressure are induced by asphyxia in neonates. We sought to define left ventricular (LV) systolic function by measuring longitudinal and radial contraction by strain Doppler echocardiography (SDE) in hypoxemic newborn pigs. Hypoxemia was induced in 11 anesthetized and instrumented newborn pigs by ventilation with $8 \% \mathrm{O}_{2}$ in nitrogen. When mean arterial blood pressure (BP) decreased to $15 \mathrm{~mm} \mathrm{Hg}$ or arterial base excess reached $-20 \mathrm{mmol} / \mathrm{L}$ or less, the pigs were reoxygenated and ventilated for $150 \mathrm{~min}$. Echocardiography was performed at baseline and during hypoxemia and reoxygenation. Baseline measurements of myocardial peak systolic strain demonstrated normal longitudinal shortening and radial thickening. During hypoxemia, systolic longitudinal shortening in the mid-posterior and septal segments changed to systolic stretching. Peak strain in the mid-lateral and anterior segments decreased but without signs of paradox wall motion. Short-axis peak strain remained positive during hypoxemia, although the amplitude was reduced and delayed with respect to timing. In the newborn pig heart, we found a complex and heterogeneous systolic pattern with distinct regional differences during global hypoxemia. Rapid changes in LV function during hypoxemia and reoxygenation are assessable by SDE, and the results indicate that longitudinal systolic contraction is more vulnerable to hypoxemic changes than radial contraction. To explore the full picture of a global hypoxemic injury, both long- and short-axis functions have to be considered. (Pediatr Res 59: 630635, 2006)
\end{abstract}

$\mathrm{N}$ eonatal asphyxia may induce myocardial dysfunction $(1,2)$. The clinical picture varies from brady- or tachycardia to cardiogenic shock $(3,4)$, and the transient abnormalities described include hypotension, myocardial ischemia, mitral and/or tricuspid regurgitation, and pulmonary hypertension $(5,6)$. During the first postnatal hours, there is an inverse relationship between tricuspid velocity and age (7),

Received April 20, 2005; accepted December 9, 2005.

Correspondence: Wenche Bakken Børke, M.D., Department of Pediatric Research, Rikshospitalet University Hospital, N-0027 Oslo, Norway; e-mail: w.b.borke@medisin.uio.no

W. B. Børke is a recipient of a research fellowship from The Norwegian Council on Cardiovascular Diseases, Oslo. This work was supported by The Norwegian Society of Anesthesiology and The Norwegian SIDS Society, Oslo, Norway.

DOI: $10.1203 / 01 . p d r .0000214846 .00318 .36$ and a relationship between low alveolar oxygen tension and increased pulmonary vascular resistance (8). The diagnosis of impaired myocardial function subsequent to a hypoxicischemic insult is of major importance to improve outcome in the asphyxiated neonates.

Traditionally, LV systolic function has been assessed by M-mode measurement of the radial movements and myocardial wall thickness. Longitudinal shortening, however, is described as an index of global LV function (9) and is significantly depressed during regional ischemia in humans and experimental animal models $(10,11)$. LV longitudinal shortening is supposed to be a sensitive marker of ischemia because the subendocardial muscle fibers of LV are the most susceptible to ischemia (12). However, LV function is a result of the combined contraction of the differently oriented muscle fibers (13).

The complex myocardial geometry is responsible for both longitudinal and radial contraction and the LV torsion (14). Previous research has studied myocardial contraction patterns, including changes in contraction during regional ischemia and reperfusion (12,15-17). Human studies have shown that longitudinal movement derived from the subendocardial and subepicardial muscle fibers slightly precede radial movements resulting from circumferential and radial fibers (18). Characteristic relations between long- and short-axis motion in healthy individuals are described, and their loss is an early index of systolic ventricular disease $(18,19)$. During studies in an adult population, the combined assessment of both radial and longitudinal LV function by tissue Doppler imaging was needed to describe LV dysfunction (20-22).

Strain Doppler echocardiography (SDE) is a new powerful noninvasive diagnostic tool to assess LV function $(23,24)$.

Abbreviations: BP, blood pressure; CO, cardiac output; cTnI, cardiac troponin I; LV, left ventricular; LVP, left ventricular pressure; RCA, right coronary artery; RV, right ventricular; RVP, right ventricular pressure; SDE, strain Doppler echocardiography; TTP, time to peak strain 
Strain is directly related to myocardial fiber shortening (change in length per unit length) and reflects deformation of myocardium. Thus, strain describes the contraction/relaxation pattern in the myocardium (25), and both longitudinal and radial strain may be assessed by this Doppler technique. Strain and strain rate have been shown to be superior to tissue Doppler velocity for measuring systolic function $(10,26)$ because neither of these modalities is influenced by segment tethering or cardiac translation (27).

The present study used SDE to assess systolic myocardial longitudinal and radial deformation during global hypoxemia and reoxygenation in newborn pigs.

\section{METHODS}

Animal preparation. Of 20 newborn Landrace pigs of either sex (age 14 to $36 \mathrm{~h}$ ) weighing $1.6-2.7 \mathrm{~kg}, 11$ pigs were selected and included in the study. Pigs were excluded after a period of recovery due to persistently low $\mathrm{BP}$ or widespread severe differences in regional functions as assessed by SDE. The pigs were anesthetized and tracheostomized as previously described (28) and mechanically ventilated with a pressure-controlled ventilator (Babylog $8000+$, Drägerwerk, Lübeck, Germany). Normoventilation $\left(\mathrm{PaCO}_{2} 4.5-6.0 \mathrm{kPa}\right)$ was achieved by adjusting peak inspiratory pressure (PIP) or ventilatory rate (30-40 breaths per minute). Inspired fraction of $\mathrm{O}_{2}$ and end-tidal $\mathrm{CO}_{2}$ were continuously monitored $\left(\mathrm{CO}_{2} \mathrm{SMO}\right.$, Respironics, Murrysville, PA). Throughout the experiment, general anesthesia was given as a continuous infusion with fentanyl $50 \mu \mathrm{g} / \mathrm{kg}$ and midazolam $0.25 \mathrm{mg} / \mathrm{kg}$ (IVAC P2000 infusion pump). A continuous i.v. infusion with Salidex (glucose $35 \mathrm{~g} / \mathrm{L}, \mathrm{NaCl}$ $50 \mathrm{mmol} / \mathrm{L}$ ) was given, and the S-glucose was kept in the range of 2$10 \mathrm{mmol} / \mathrm{L}$. The electrocardiogram was continuously monitored using limb leads. Rectal temperature was maintained between 38 and $40^{\circ} \mathrm{C}$ with a heating blanket and a radiant heating lamp. A suction catheter was placed into the gastric ventricle to empty any air.

The animals were cared for and handled in accordance with the European Guidelines for Use of Experimental Animals, and the experimental protocol was approved by the Norwegian Council for Animal Research.

Experimental protocol. The animals were stabilized for $1 \mathrm{~h}$ after the initial procedures. Hypoxemia was then achieved by ventilation with a gas mixture of $8 \% \mathrm{O}_{2}$ in $\mathrm{N}_{2}$ until either mean arterial $\mathrm{BP}$ decreased to $15 \mathrm{~mm} \mathrm{Hg}$ or base excess reached $-20 \mathrm{mmol} / \mathrm{L}$. The pigs were then reoxygenated with ambient air or $100 \%$ oxygen for $30 \mathrm{~min}$ and further ventilated with ambient air for another $120 \mathrm{~min}$. Because there were no differences between the pigs as assessed by SDE, the results are combined. At the end of the experiment, the piglets were given an overdose of $150 \mathrm{mg} / \mathrm{kg}$ i.v. pentobarbital.

Pressure measurements. The femoral artery and left external jugular vein were cannulated (polyethylene catheters Portex PE-50, Portex Ltd. Hythe, Kent, UK) for blood sampling and continuous monitoring of arterial BP.

Guided by ultrasound, a 2-French micromanometer-tipped catheter (MPC500, Millar catheter, Millar Instruments, Houston, TX) was inserted from the left carotid artery to the left ventricle for continuous monitoring of the left ventricular pressure (LVP). The pressure transducers were calibrated with a water column. The pressure data were processed and digitized for analysis. We managed to perform LVP measurements in nine pigs; the Millar catheter entered either a papillary muscle or ventricular wall in the remaining two pigs.

Systolic right ventricular pressure (RVP) was calculated indirectly as the sum of the central venous pressure and the pressure gradient between the right ventricle and the right atrium $(\mathrm{mm} \mathrm{Hg})$, by sampling the peak tricuspid regurgitation velocity $\left(\mathrm{TR}-\mathrm{V}_{\max }, \mathrm{m} / \mathrm{s}\right)$ using the modified Bernoulli's equation (29).

Echocardiography. We used a Vivid 7 digital ultrasound scanner (GE VingMed Ultrasound, Horten, Norway) with an integrated program for quantitative analysis (EchoPAC GE Vingmed). The transducer was a combined tissue imaging and Doppler transducer (10S) with a frequency range of 4.0-11.0 MHz. The recordings were mainly obtained using 8.0 MHz. The strain images were obtained with a frame rate varying between 180 and 250 frames per second. Digital data were recorded over three consecutive heart cycles and analyzed offline.

Two investigators, one handling the probe and one operating the scanner, performed all ultrasound examinations. The data were sampled when both agreed that the imaging quality was optimal. The first examination was performed to exclude congenital heart defects with the pigs lying in a right lateral, semisupine position. The aortic valve diameter was measured from two-dimensional parasternal long-axis views from inner edge to inner edge at the base of the aortic valve leaflets before guiding the insertion of the Millar catheter (30). The aortic valve diameter was later used for all calculations of cardiac output (CO). Aortic valve closure and systolic time (milliseconds) were analyzed offline and averaged over five consecutive cardiac cycles from aortic flow traces. When heart rate from the aortic traces differed more than 10 beats per minute from heart rate in strain recordings, we synchronized LV $\mathrm{dP} / \mathrm{dt}$ traces with strain curves and regarded peak negative $\mathrm{LV} \mathrm{dP} / \mathrm{dt}$ as end systole to define aortic valve closure.

Further studies were performed with the pigs lying in a left lateral, semisupine position. Ultrasonographic studies were performed at baseline, after $30 \mathrm{~min}$ of hypoxemia, at the start of reoxygenation, and at $150 \mathrm{~min}$ of reoxygenation. Standard subcostal apical two-chamber (2ch) and fourchamber $(4 \mathrm{ch})$ views and parasternal short-axis views were used. Separate longitudinal loops were obtained to focus on the septum and the lateral wall. Sample volume was set to $2 \mathrm{~mm}$ for short-axis measurement and $5 \mathrm{~mm}$ for longitudinal measurement. Offline analyses were averaged over three consecutive cardiac cycles. Longitudinal peak strain was assessed at mid-anterior, posterior, lateral, and septal segments. In short-axis views, radial peak strain values were assessed in the anterior septum and posterior wall segments. The strain data were calculated and averaged from all three cardiac cycles. The region of interest in the two-dimensional image was repositioned during the heart cycle to compensate for the movement of the heart. This corrected strain trace was used for processing. To assess intra- and interobserver variability, all echocardiographic recordings were analyzed twice by one observer. The posterior segment was independently analyzed both from long- and short axis views by a second observer.

$\mathrm{CO}$ was calculated from aortic flow as systolic velocity integral $\times$ valve area $\times$ heart rate. All ultrasound measurements used in the final calculations for each pig were mean values, automatically calculated in the ultrasound instrument, using measurements from three to five selected sequential good quality cycles.

Biochemical assessments. Hemoglobin ( $\mathrm{Hb})$ - and temperature-corrected acid/base status were measured as previously described (28). Blood sampling for analyzing cardiac troponin $\mathrm{I}(\mathrm{cTnI})$ was collected at baseline and at the end of the study, centrifuged, and kept at $-70^{\circ} \mathrm{C}$ until analyses were performed (AIO immunoanalyzer, Innotrac, Turku, Finland).

Statistics. Values are expressed as mean \pm SEM. Statistical analyses were performed with SPSS 11, a $t$ test for paired data, or analysis of variance (ANOVA) with repeated measurements of the studied variables. Due to skewed distribution of cTnI, these variables were log-transformed. A level of $p<0.05$ was considered as statistically significant. Intra- and interobserver agreements were assessed by the intraclass correlation coefficient $\left(\mathrm{R}_{\mathrm{ic}}\right)$ mean differences $( \pm \mathrm{SD})(31)$.

\section{RESULTS}

Hemodynamic and biochemical changes. The hemodynamic data are summarized in Table 1 . Mean baseline $\mathrm{Hb}$ was $6.8 \pm 0.3 \mathrm{~g} / \mathrm{L}$, and $\mathrm{Ca}^{2+} 1.4 \pm 0.2 \mathrm{mmol} / \mathrm{L}$. Hypoxemia time was $62 \pm 7 \mathrm{~min}$, and an inverse relationship was found between duration of hypoxemia and increasing age of the piglets $(p=0.032)$. No pigs had any cardiac malformation or a patent ductus arteriosus at the first examination. In two pigs, the duct reopened with a left-right shunting during the reoxygenation period. There was no difference in other hemodynamic data or strain measurements in these two pigs compared with the pigs with a closed duct.

CTnI increased from the baseline $0.05 \pm 0.004 \mu \mathrm{g} / \mathrm{L}$ to end of the study $0.2 \pm 0.05 \mu \mathrm{g} / \mathrm{L}(p<0.01)$, confirming a severe hypoxic injury. $\mathrm{LV} \mathrm{dP} / \mathrm{dt}_{\max }$ decreased substantially during the experiment as a result of impaired contractility. Systemic BP and systolic LVP decreased considerably concomitant with an increased systolic RVP exceeding both diastolic and systolic BP (Fig. 1). CO per kg increased initially during hypoxemia, but decreased toward the end of the hypoxic injury.

Two piglets died because of AV block after 20 and 50 min of reoxygenation. In the nine surviving piglets, all hemody- 
Table 1. Hemodynamic characteristics and blood gas variables

\begin{tabular}{lcccc}
\hline & Baseline & 30 min hypoxemia & Start reoxygenation & 150 min reoxygenation \\
\hline Heart rate $(\mathrm{bpm})$ & $144 \pm 13$ & $213 \pm 8$ & $165 \pm 9$ & $152 \pm 12^{*}$ \\
$\mathrm{CO} \mathrm{per} \mathrm{kg}(\mathrm{L} / \mathrm{min} / \mathrm{kg})$ & $0.30 \pm 0.02$ & $0.37 \pm 0.04$ & $0.25 \pm 0.03$ & $45 \pm 8$ \\
$\mathrm{LVP}$ & $52 \pm 7$ & $6.34 \pm 0.03 \dagger$ \\
$\mathrm{LV} \mathrm{dPdt}$ & $(\mathrm{mm} \mathrm{Hg})$ & $9023 \pm 1335$ & $6315 \pm 1209$ & $65 \pm 4^{*}$ \\
$\mathrm{pH}$ & $149 \pm 70 \pm 2214$ & $7.35 \pm 0.03$ & $7.10 \pm 0.02$ & $10,682 \pm 1519^{*}$ \\
$\mathrm{BE}(\mathrm{mmol} / \mathrm{L})$ & $7.47 \pm 0.03$ & $-5.9 \pm 1.9$ & $-20.0 \pm 0.7$ & $7.38 \pm 0.02^{*}$ \\
$\mathrm{PaO}_{2}(\mathrm{~mm} \mathrm{Hg})$ & $4.9 \pm 1.1$ & $3.2 \pm 0.2$ & $3.9 \pm 0.2$ & $-0.5 \pm 1.4^{*}$ \\
$\mathrm{Paco}_{2}(\mathrm{~mm} \mathrm{Hg})$ & $10.1 \pm 0.4$ & $4.9 \pm 0.2$ & $4.3 \pm 0.2$ & $9.4 \pm 0.3^{*}$ \\
$\mathrm{Saturation}$ & $5.3 \pm 0.1$ & $32 \pm 1.8$ & $34 \pm 2.2$ & $5.7 \pm 0.1^{*}$ \\
\hline
\end{tabular}

Statistical analysis is performed by ANOVA with repeated measurements reflecting the experiment time course.

$* p<0.001 ; \dagger p<0.01$.

$\mathrm{BE}$, base excess; $\mathrm{LVP}_{\max }, \mathrm{LVP} ; \mathrm{PaO}_{2}$, arterial oxygen tension; $\mathrm{PaCO}_{2}$, arterial carbon dioxide tension.

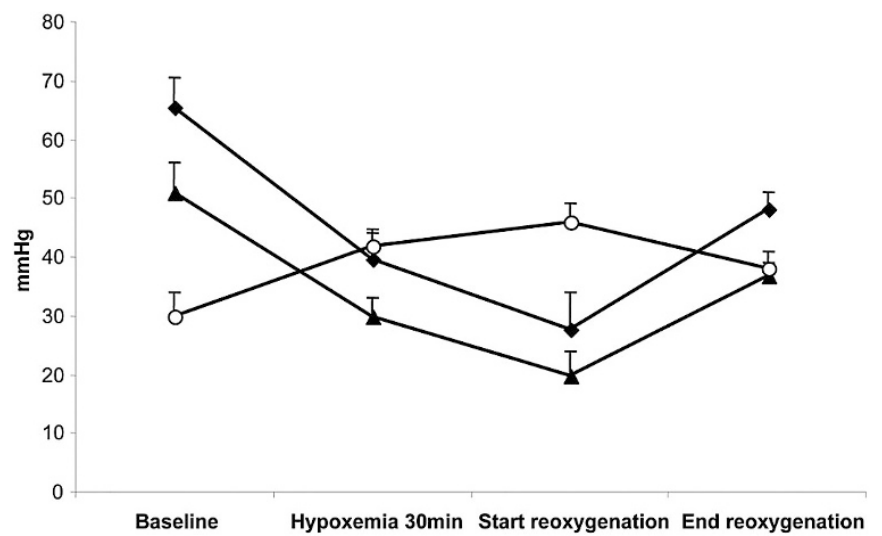

Figure 1. Hemodynamics and blood gas variables. Hemodynamic changes during the experiment. Systolic BP $(\diamond)$, RVP $(\bigcirc)$, diastolic BP $(\mathbf{\Delta})$.

namic data had improved considerably at 150 min of reoxygenation, and restoration of LV function was partly established. The hemodynamic variables were, however, not completely restored to baseline values after $150 \mathrm{~min}$.

Strain results. Table 2 shows time of systole, peak systolic strain values, and time to peak strain (TTP) at the apical 2ch and $4 \mathrm{ch}$ views in mid-posterior, lateral, anterior, and septal segments, and the anterior septum and posterior wall segment from short axis view.
At baseline, the pigs had negative systolic peak strain values in apical long-axis views as a sign of normal contraction. Short-axis peak strain was positive, demonstrating normal systolic thickening. Figure 2 demonstrates representative recordings of myocardial strain by Doppler echocardiography during hypoxemia. Radial systolic strains remained positive, showing thickening during hypoxemia, but maximum values were decreased and delayed. In contrast, longitudinal systolic strain became positive, showing a paradoxical lengthening in the septal and posterior segments. In the anterior and lateral segments, peak longitudinal strain values were decreased but remained negative. TTP was significantly delayed in all segments both during longitudinal and radial contractions (Fig. 2; Table 2). During severe hypoxemia, peak strain values were delayed after aortic valve closure and end systole. After 150 min of reoxygenation, the strain values were partly restored. Even though restoration was initiated, there was still systolic paradoxical lengthening present in the posterior wall and septum in four and two pigs, respectively. At $150 \mathrm{~min}$ of reoxygenation, peak strain values were still delayed after aortic valve closure in three pigs.

Strain-pressure loops (Fig. 3) were constructed to further explore the different impact on longitudinal and radial LV function caused by hypoxemia. The baseline strain-pressure loops demonstrated shortening during systole for longitudinal

Table 2. Strain values (\%) and timing (ms) in long-and short-axis views

\begin{tabular}{|c|c|c|c|c|c|c|c|c|}
\hline Strain value, $\%$ & Baseline & $\begin{array}{c}30 \mathrm{~min} \\
\text { hypoxemia }\end{array}$ & $\begin{array}{c}\text { Start } \\
\text { reoxygenation }\end{array}$ & $\begin{array}{c}150 \mathrm{~min} \\
\text { reoxygenation }\end{array}$ & $\begin{array}{l}\text { Baseline } \\
\text { TTP, ms }\end{array}$ & $\begin{array}{c}30 \mathrm{~min} \\
\text { hypoxemia } \\
\text { TTP, ms }\end{array}$ & $\begin{array}{c}\text { Start } \\
\text { reoxygenation } \\
\text { TTP, ms }\end{array}$ & $\begin{array}{c}150 \mathrm{~min} \\
\text { reoxygenation } \\
\mathrm{TTP}, \mathrm{ms}\end{array}$ \\
\hline \multicolumn{9}{|l|}{ Apical 4ch, 2ch } \\
\hline Mid-septum & $-18 \pm 1$ & $6 \pm 4$ & $7 \pm 4$ & $-4 \pm 4^{*}$ & $147 \pm 9$ & $163 \pm 11$ & $160 \pm 13$ & $174 \pm 11 \dagger$ \\
\hline Mid-lateral & $-20 \pm 2$ & $-8 \pm 3$ & $-7 \pm 2$ & $-10 \pm 3 \ddagger$ & $177 \pm 11$ & $177 \pm 10$ & $187 \pm 10$ & $191 \pm 10 \dagger$ \\
\hline Mid-anterior & $-16 \pm 2$ & $-6 \pm 3$ & $-5 \pm 2$ & $-14 \pm 2 \dagger$ & $149 \pm 10$ & $155 \pm 10$ & $200 \pm 12$ & $156 \pm 9 \dagger$ \\
\hline Anterior septum & $16 \pm 2$ & $12 \pm 2$ & $9 \pm 1$ & $21 \pm 8 \dagger$ & $102 \pm 9$ & $125 \pm 9$ & $146 \pm 11$ & $111 \pm 6 \ddagger$ \\
\hline $\begin{array}{l}\text { Aortic valve closure, } \\
\text { time of end } \\
\text { systole }\end{array}$ & & & & & $180 \pm 11$ & $142 \pm 9$ & $156 \pm 9$ & $150 \pm 7$ \\
\hline
\end{tabular}

Statistical analysis is performed by ANOVA with repeated measurements reflecting the experiment time course. Difference between systole time and TTP was performed using a $t$ test.

$* p<0.001 ; \dagger p<0.01 ; \ddagger p<0.05$. 


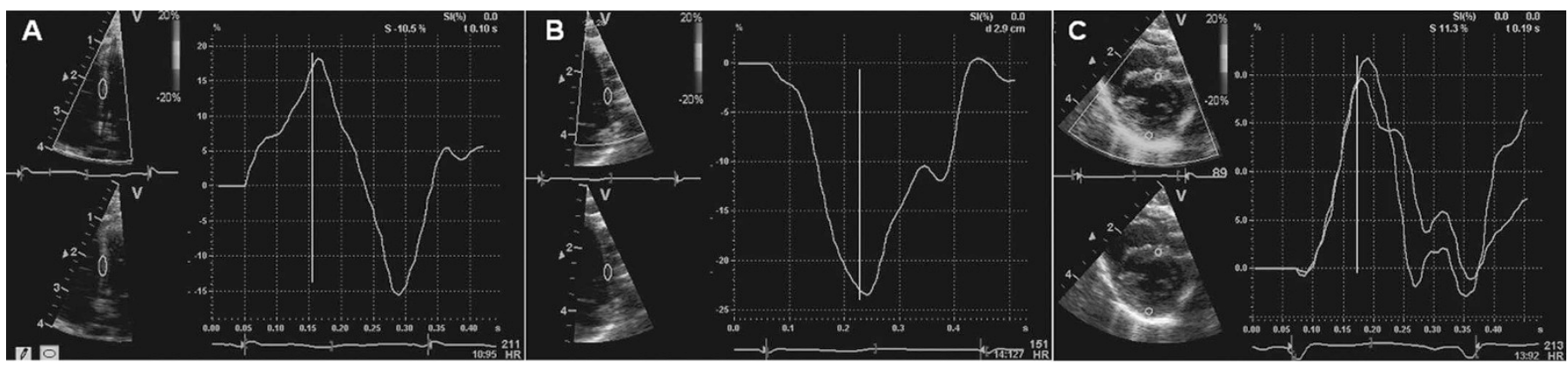

Figure 2. Strain curves. Representative longitudinal strain curves in septum $(A)$ and lateral wall $(B)$, and radial strain curves $(C)$ by SDE during hypoxemia. Longitudinal systolic strain became positive, showing a paradox lengthening in the septal and posterior segments, while radial systolic strains remained positive, showing thickening during hypoxemia, although maximum values were decreased and delayed. TTP is delayed after aortic valve closure (white line) in both longitudinal and radial strains.
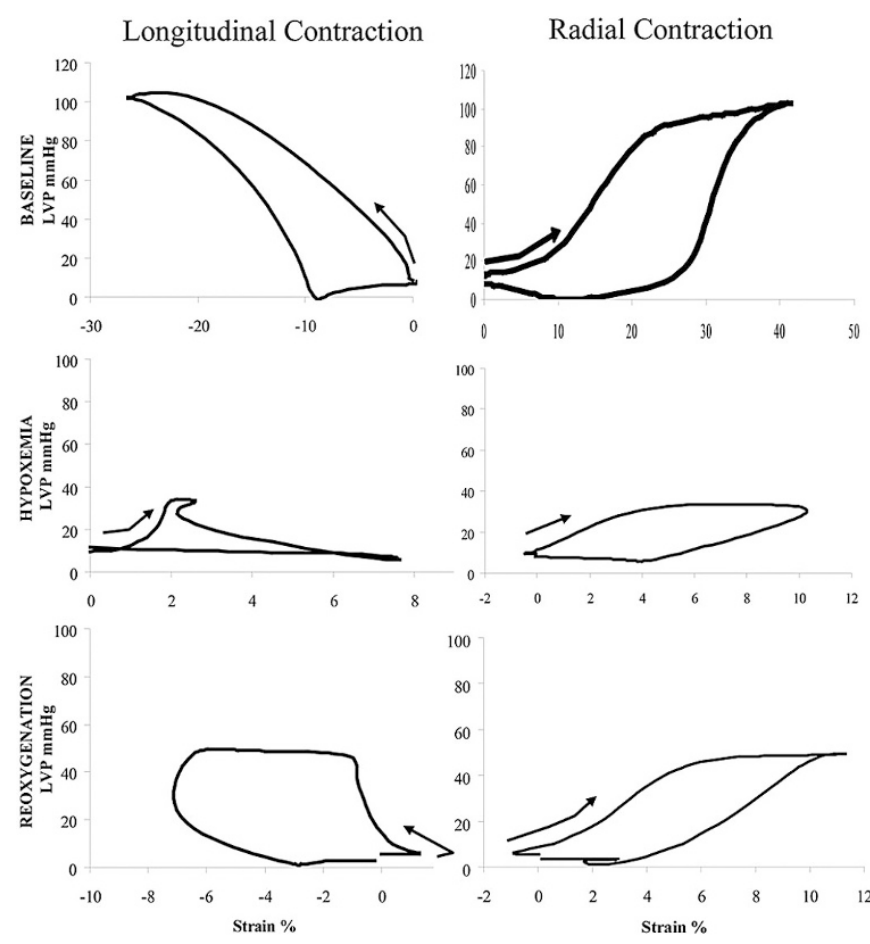

Figure 3. Strain-pressure loops. Longitudinal and radial strain-pressure loops at baseline during hypoxemia and reoxygenation. The areas within the strain-pressure loops represent myocardial work. Hypoxemia induced a decrease in the area within the strain-pressure loops, demonstrating a considerably compromised myocardium and diminished myocardial work. Systole begins at the arrows, and the highest point of the loops represents $L \mathrm{PP}_{\max }$. In contrast to a normal counterclockwise rotation, the longitudinal strainpressure loop inverts and rotates clockwise during hypoxemia, and the shape becomes more irregular. The radial strain-pressure loops in short-axis views rotate clockwise at baseline and during hypoxemia, and the shape of the loops was mainly preserved.

measurements and systolic thickening for radial measurements. The areas within the strain-pressure loops represent myocardial work. Induction of global hypoxemia caused a concomitant and marked decrease in the area of the loops compared with baseline in both the longitudinal and the radial directions, demonstrating a considerably compromised myocardial function and lowered myocardial work. Furthermore, the radial contraction pattern, consisting of thickening during systole, was conserved during hypoxemia. Although the myocardial work was lowered, the loops in short-axis views still rotated clockwise and the shape of the loops was mainly preserved. Longitudinal measurements showed stretching during systole. Contrary to the normal baseline counterclockwise longitudinal strain-pressure loop, the longitudinal strainpressure loops rotated clockwise during hypoxemia, and the shape became more irregular.

Reproducibility. All recordings in the posterior segment from parasternal short-axis and apical long-axis views were analyzed by two observers. Inter- and intraobserver variations were expressed as mean differences $( \pm$ SD) and intraclass correlation coefficient $\left(\mathrm{R}_{\mathrm{ic}}\right)$. Mean differences for interobserver variability were $-0.72 \pm 2.2 \%$ and $1.4 \pm 2.3 \%, \mathrm{R}_{\mathrm{ic}}$ were 0.90 and 0.82 , respectively, indicating good agreement. Mean differences in intraobserver variation were $0.16 \pm 1.6 \%$ and $0.17 \pm 1.6 \%$ and $R_{i c}$ were 0.95 and 0.96 , respectively.

\section{DISCUSSION}

The most striking finding in this study was that hypoxemia caused severe changes in longitudinal deformation whereas changes in radial deformation were more moderate. During hypoxemia longitudinal strain showed paradoxical stretching, while radial strain continued to demonstrate thickening. The peak amplitude of radial strain was, however, decreased and delayed. In addition, the changes in the longitudinal myocardial contraction were heterogeneous during hypoxemia. Longitudinal peak strain values were different in septal and posterior segments, compared with lateral and anterior segments. These findings suggest that longitudinal contraction may be more vulnerable to global hypoxemia than radial contraction in newborn pigs. Accordingly, in cases when radial functions appear conserved, longitudinal strain assessments may be necessary to explore possible hypoxemic injury of the myocardium.

The increased $\mathrm{CO}$ in the early phase of hypoxia was probably a result of increased heart rate (7), as neonates regulate their $\mathrm{CO}$ mainly by regulating heart rate (32). Tachycardia also leads to shorter diastole and reduced myocardial perfusion time. During the hypoxemic injury, BP decreased and the pigs became acidotic. Acidosis has a negative inotropic effect, as low $\mathrm{pH}$ may reduce the binding of calcium of the troponin complex (33). Accordingly, there was a marked decrease in $\mathrm{CO}$ toward the end of the hypoxemic insult, even 
though the heart rate was still increased except in three piglets with sudden bradycardia. Systolic RVP increased concomitantly, exceeding systemic BP. Subendocardial fibers probably are the first muscle fibers that become ischemic when an imbalance in oxygen delivery or coronary blood supply occurs $(12,34)$. Hypoperfusion has been associated with decreased longitudinal strain, followed by diminished circumferentially and finally radial function in an animal model (35), which agrees with the observed differences in the longitudinal and radial contraction pattern in the hypoxic pigs.

When RVP equals or exceeds LVP and systemic BP, there may be changes in intraventricular septum affecting LV filling and myocardial contraction (36). This may contribute to the impaired contraction in the interventricular septum as assessed by changes in long-axis SDE. When the RVP increase is too high, the systolic pressure gradient across the right coronary artery (RCA) is reversed (37), probably leading to decreased myocardial blood supply as the amount of RCA perfusion is found inversely related to the level of pulmonary hypertension (38). Porcine myocardial posterior wall and parts of septum are predominantly supplied from the RCA (39). Altered myocardial perfusion in the RCA territory during hypoxemia may explain why longitudinal peak strain values in the posterior and septal segments were more abnormal than peak strain in anterior and lateral segments. Further studies are necessary to evaluate this.

LV function is determined by the complex spiral orientation of the muscle fibers. Variations in fiber orientation, as well as biochemical, nutritional, and mechanical differences in muscle layers during hypoxemia may influence contraction. Longitudinal movements result from the contraction of subendocardial and subepicardial muscle fibers. Radial movement derives mainly from contraction of circumferential fibers (18). As a result of different fiber directions, combined analysis of longitudinal and radial function allows the separation of a composite function of different fibers, which may lead to an improved understanding of the progression of dysfunction. In the present study, longitudinal function of the left ventricle, involving motion of the atrioventricular plane toward the apex was diminished. The decrease in longitudinal strain was heterogeneous. The longitudinal peak strain in the septum and the posterior wall, demonstrating paradoxical deformation with stretching, was in sharp contrast to the peak strain in the anterior and lateral walls showing shortening, as well as to the radial peak strain, which consistently demonstrated thickening, although the peak strain values were decreased and delayed. Changes in the activation sequence of long- and short-axis deformation may partly account for the differences observed $(19,40)$. During hypoxemia, TTP was delayed after aortic valve closure into early diastole in segments with apparently preserved deformation pattern. This finding was present both in long- and short-axis views as a sign of ischemia and compromised myocardial performance (41). This feature is described as postsystolic shortening $(11,42)$.

In this study, we found that global hypoxemia caused severe changes in longitudinal deformation, whereas changes in radial deformation were more moderate. Accordingly, in cases in which radial contraction seems to be preserved, as shown by conventional echocardiography or radial strain measurements, longitudinal strain assessments have to be performed to exclude hypoxemic injury of the myocardium. In the neonatal intensive care unit, it may be difficult to differentiate between low BP due to myocardial dysfunction and low peripheral resistance as in septicemia. The exact diagnosis of myocardial function may add important information for treatment strategies in seriously ill children. This study is a practical approach to a thorough examination of systolic dysfunction of the newborn. Strain measurements can easily be applied in a clinical setting. Data can be acquired bedside and analyzed instantaneously.

Study Limitations. Strain measurements are angle dependent. For each acquisition, care was taken to direct the Doppler beam parallel to the myocardial segment of interest. In long-axis views, separate loops were obtained to focus on the septum and lateral wall. The present tissue Doppler method cannot be used to differentiate function between the myocardial layers. In the present study, all the piglets were heavily anesthetized and instrumented. Even though we allowed a period of recovery after the initial procedures and care was taken to minimize myocardial damage, baseline values may be impaired compared with healthy, noninstrumented conscious pigs.

\section{CONCLUSION}

A complex and heterogeneous systolic pattern with distinct regional differences was found during global hypoxemia in newborn pigs. These findings indicate that the longitudinal myocardial function is more vulnerable to hypoxemic changes than the radial function as assessed by SDE, which represents a powerful diagnostic tool to diagnose compromised myocardium in newborns. The combined analyses of contraction in both long- and short-axis views provide complementary information on the variation of myocardial performance. To explore the full picture of a global hypoxemic injury, both longitudinal and radial systolic functions need to be addressed.

Acknowledgments. The authors thank J. C. Aasmul, G. E. Medirad, A. S. and A. Steiro, and L. Mørkrid, Department of Clinical Chemistry, for excellent technical assistance. They are also grateful for valuable advice from G. Aamodt, M.Sc., Ph.D., Section of Biostatistics, Rikshospitalet University Hospital.

\section{REFERENCES}

1. Williams CE, Mallard C, Tan W, Gluckman PD 1993 Pathophysiology of perinatal asphyxia. Clin Perinatol 20:305-325

2. Borke WB, Munkeby BH, Halvorsen B, Bjornland K, Tunheim SH, Borge GI, Thaulow E, Saugstad OD 2004 Increased myocardial matrix metalloproteinases in hypoxic newborn pigs during resuscitation: effects of oxygen and carbon dioxide. Eur J Clin Invest 34:459-466

3. Walther FJ, Siassi B, Ramadan NA, Wu PY 1985 Cardiac output in newborn infants with transient myocardial dysfunction. J Pediatr 107:781-785

4. Tapia-Rombo CA, Carpio-Hernandez JC, Salazar-Acuna AH, Alvarez-Vazquez E, Mendoza-Zanella RM, Perez-Olea V, Rosas-Fernandez C 2000 Detection of transitory myocardial ischemia secondary to perinatal asphyxia. Arch Med Res 31:377383

5. Ranjit MS 2000 Cardiac abnormalities in birth asphyxia. Indian J Pediatr 67:529532

6. Rowe RD, Hoffman T 1972 Transient myocardial ischemia of the newborn infant: a form of severe cardiorespiratory distress in full-term infants. J Pediatr 81:243-250 
7. Fugelseth D, Borke WB, Lenes K, Matthews I, Saugstad OD, Thaulow E 2005 Restoration of cardiopulmonary function with $21 \%$ versus $100 \%$ oxygen after hypoxaemia in newborn pigs. Arch Dis Child Fetal Neonatal Ed 90:F229-F234

8. Hambraeus-Jonzon K, Bindslev L, Mellgard AJ, Hedenstierna G 1997 Hypoxic pulmonary vasoconstriction in human lungs: a stimulus-response study. Anesthesiology 86:308-315

9. Gulati VK, Katz WE, Follansbee WP, Gorscsan J 3rd 1996 Mitral annular descent velocity by tissue Doppler echocardiography as an index of global left ventricular function. Am J Cardiol 77:979-984

10. Edvardsen T, Skulstad H, Aakhus S, Urheim S, Ihlen H 2001 Regional myocardial systolic function during acute myocardial ischemia assessed by strain Doppler echocardiography. J Am Coll Cardiol 37:726-730

11. Skulstad H, Edvardsen T, Urheim S, Rabben SI, Stugaard M, Lyseggen E, Ihlen H, Smiseth OA 2002 Postsystolic shortening in ischemic myocardium: active contraction or passive recoil? Circulation 106:718-724

12. Henein MY, Gibson DG 1999 Long axis function in disease. Heart 81:229-23

13. Greenbaum RA, Ho SY, Gibson DG, Becker AE, Anderson RH 1981 Left ventricular fibre architecture in man. Br Heart J 45:248-263

14. Moore CC, Lugo-Olivieri CH, McVeigh ER, Zerhouni EA 2000 Three-dimensional systolic strain patterns in the normal human left ventricle: characterization with tagged MR imaging. Radiology 214:453-466

15. Pislaru C, Belohlavek M, Bae RY, Abraham TP, Greenleaf JF, Seward JB 2001 Regional asynchrony during acute myocardial ischemia quantified by ultrasound strain rate imaging. J Am Coll Cardiol 37:1141-1148

16. Hexeberg E, Birkeland S, Grong K, Matre K, Lekven J 1992 Coronary artery stenosis provokes non-uniformity of two-dimensional deformation in the anterior wall of the feline left ventricle. Eur Heart J 13:981-989

17. Gallagher KP, Stirling MC, Choy M, Szpunar CA, Gerren RA, Botham MJ, Lemmer JH 1985 Dissociation between epicardial and transmural function during acute myocardial ischemia. Circulation 71:1279-1291

18. Jones CJ, Raposo L, Gibson DG 1990 Functional importance of the long axis dynamics of the human left ventricle. Br Heart J 63:215-220

19. Oki T, Tabata T, Mishiro Y, Yamada H, Abe M, Onose Y, Wakatsuki T, Iuchi A, Ito S 1999 Pulsed tissue Doppler imaging of left ventricular systolic and diastolic wall motion velocities to evaluate differences between long and short axes in healthy subjects. J Am Soc Echocardiogr 12:308-313

20. Cain P, Short L, Baglin T, Case C, Bosch HG, Marwick TH 2002 Development of a fully quantitative approach to the interpretation of stress echocardiography using radial and longitudinal myocardial velocities. J Am Soc Echocardiogr 15:759-767

21. Quintana M, Saha SK, Rohani M, Del Furia F, Bjernby J, Lind B, Brodin LA 2004 Assessment of the longitudinal and circumferential left ventricular function at rest and during exercise in healthy elderly individuals by tissue-Doppler echocardiography: relationship with heart rate. Clin Sci 106:451-457

22. Oki T, Iuchi A, Tabata T, Mishiro Y, Yamada H, Abe M, Onose Y, Wakatsuki T, Ito S 1999 Left ventricular systolic wall motion velocities along the long and short axes measured by pulsed tissue Doppler imaging in patients with atrial fibrillation. J Am Soc Echocardiogr 12:121-128

23. Urheim S, Edvardsen T, Torp H, Angelsen B, Smiseth OA 2000 Myocardial strain by Doppler echocardiography. Validation of a new method to quantify regional myocardial function. Circulation 102:1158-1164

24. Heimdal A, Stoylen A, Torp H, Skjaerpe T 1998 Real-time strain rate imaging of the left ventricle by ultrasound. J Am Soc Echocardiogr 11:1013-1019
25. Mirsky I, Parmley WW 1973 Assessment of passive elastic stiffness for isolated heart muscle and the intact heart. Circ Res 33:233-243

26. Greenberg NL, Firstenberg MS, Castro PL, Main M, Travaglini A, Odabashian JA Drinko JK, Rodriguez LL, Thomas JD, Garcia MJ 2002 Doppler-derived myocardial systolic strain rate is a strong index of left ventricular contractility. Circulation 105:99-105

27. Abraham TP, Nishimura RA, Holmes DR, Jr. Belohlavek M, Seward JB 2002 Strain rate imaging for assessment of regional myocardial function: results from a clinical model of septal ablation. Circulation 105:1403-1406

28. Borke WB, Munkeby BH, Morkrid L, Thaulow E, Saugstad OD 2004 Resuscitation with $100 \% \mathrm{O}(2)$ does not protect the myocardium in hypoxic newborn piglets. Arch Dis Child Fetal Neonatal Ed 89:F156-F160

29. Skjaerpe T, Hatle L 1986 Noninvasive estimation of systolic pressure in the right ventricle in patients with tricuspid regurgitation. Eur Heart J 7:704-710

30. Ihlen H, Myhre E, Pamlie J, Forfang K, Larsen S 1985 Changes in left ventricular stroke volume measured by Doppler echocardiography. Br Heart J 54:378-383

31. Bland JM, Altman DG 1999 Measuring agreement in method comparison studies. Stat Methods Med Res 8:135-160

32. Friedman WF 1972 The intrinsic physiologic properties of the developing heart Prog Cardiovasc Dis 15:87-111

33. Nakanishi T, Okuda H, Nakazawa M, Takao A 1985 Effect of acidosis on contractile function in the newborn rabbit heart. Pediatr Res 19:482-488

34. Gold FL, Bache RJ 1982 Transmural right ventricular blood flow during acute pulmonary artery hypertension in the sedated dog. Evidence for subendocardial ischemia despite residual vasodilator reserve. Circ Res 51:196-204

35. Moore CC, McVeigh ER, Zerhouni EA 1999 Noninvasive measurement of threedimensional myocardial deformation with tagged magnetic resonance imaging during graded local ischemia. J Cardiovasc Magn Reson 1:207-222

36. Marcus JT, Vonk Noordegraaf A, Roeleveld RJ, Postmus PE, Heethaar RM, van Rossum AC, Boonstra A 2001 Impaired left ventricular filling due to right ventricular pressure overload in primary pulmonary hypertension: noninvasive monitoring using MRI. Chest 119:1761-1765

37. Fixler DE, Archie JP, Ullyot DJ, Buckberg GD, Hoffman JI 1973 Effects of acute right ventricular systolic hypertension on regional myocardial blood flow in anesthetized dogs. Am Heart J 85:491-500

38. Akasaka T, Yoshikawa J, Yoshida K, Hozumi T, Takagi T, Okura H 1996 Comparison of relation of systolic flow of the right coronary artery to pulmonary artery pressure in patients with and without pulmonary hypertension. Am J Cardiol 78:240-244

39. Weaver ME, Pantely GA, Bristow JD, Ladley HD 1986 A quantitative study of the anatomy and distribution of coronary arteries in swine in comparison with other animals and man. Cardiovasc Res 20:907-917

40. Pai RG, Gill KS 1998 Amplitudes, durations, and timings of apically directed left ventricular myocardial velocities: I. Their normal pattern and coupling to ventricular filling and ejection. J Am Soc Echocardiogr 11:105-111

41. Brown MA, Norris RM, Takayama M, White HD 1987 Post-systolic shortening: a marker of potential for early recovery of acutely ischaemic myocardium in the dog. Cardiovasc Res 21:703-716

42. Gibson D, Mehmel H, Schwarz F, Li K, Kubler W 1986 Changes in left ventricular regional asynchrony after intracoronary thrombolysis in patients with impending myocardial infarction. Br Heart J 56:121-130 